\title{
Use of geospatial information system based tool for renovation and rehabilitation of water distribution systems
}

\author{
${ }^{1 *}$ M. Tabesh; ${ }^{2}$ M. R. Delavar; ${ }^{3}$ A. Delkhah \\ ${ }^{1}$ Center of Excellence for Infrastructures Engineering and Management, School of Civil Engineering, College of \\ Engineering, University of Tehran, Tehran, Iran \\ ${ }^{2}$ Center of Excellence in Geomatics Engineering and Disaster Management, Department of Surveying and \\ Geomatic Engineering, College of Engineering, University of Tehran, Tehran, Iran \\ ${ }^{3}$ Department of Surveying and Geomatic Engineering, College of Engineering, University of Tehran, Tehran, Iran \\ Received 26 August 2008; $\quad$ revised 4 April 2009; accepted 8 September 2009; available online 1 December 2009
}

\begin{abstract}
Normally, decision makers use number of pipe broken in specific sections of water distribution systems to determine the pipes to be replaced. This index cannot solely evaluate hydraulic and quality parameters of the system and effects of pipe renovation on the system performance. In this study, a methodology is presented to manage the rehabilitation and replacement of water distribution network using hydraulic and geospatial information systems models. A preprocessor subroutine is developed to link geospatial information systems and hydraulic software. Hydraulic parameters together with the attribute data of pipes are used to determine the required renovation schemes based on several criteria. The proposed indices consist of pipe breaks and leakage analyses, hydraulic and quality performance and mechanical reliability of the network. A novel approach is also introduced to calculate leakage values throughout the network. Results of a real case study by the developed model introduced replacement of $4 \mathrm{~km} 40 \mathrm{~mm}$ galvanized pipes instead of $11 \mathrm{~km} 100 \mathrm{~mm}$ asbestos-cement pipes from conventional method. It is observed that the suggested geographic information system based model produces more realistic results with less cost for renovation schemes in comparison with conventional method which just consider number of bursts as a key criterion.
\end{abstract}

Keywords: Geospatial information systems; Hydraulic model; Leakage; Pressure; Quality; Rehabilitation; Reliability; Water distribution systems

\section{INTRODUCTION}

Operation of a water distribution system is affected by a number of parameters (e.g., pipe type, quality of components and construction procedure, hydraulic performance, pressure and quality of operation). For these reasons, so many pipes' bursts and accidents are occurring in a water network. Pipe failure in water distribution networks wastes the financial and human capital (for repair and restoration of the network) and reduces the reliability of the network due to higher head loss or interrupting the water supply in parts of the distribution network and the outcome dissatisfied customers. Various solutions are available for these problems. Active strategies rely on pipe failure forecasting with reduction in number of accidents. It will not only save money and increase the revenues, but also will improve the level of service, increase the

ه*Corresponding Author Email: mtabesh@ut.ac.ir Tel.: +9821 6111 2258, Fax: +9821 66403808 satisfaction of customers, enhance the life of the network and reliability of the system (Soltani, 2009).

Based on Elahipanah (1998) and Tashayoee (2005), the current costs of maintenance and traditional repairs of Iranian water distribution networks show a conspicuous rise from 1999 to 2002. Water distribution networks of Iran experienced about 1 million accidents in 1998 which more than $20 \%$ of the total annual incomes of water and wastewater companies was expended for their repair, configuration and offsetting the losses caused by the breaks (Baygi, 1999). During 1999 and 2000 about 260,000 and 320,000 accidents on main pipes and approximately 700,000 and 800,000 accidents on service pipes have been reported in Iranian water distribution networks, respectively. In these two years, about 1,800 and 1,900 km of pipes has been replaced, respectively. Replacement of $1 \mathrm{~km}$ pipe requires 200 to 400 Million Rials (21000-42000 USD) 
money expenditure (Elahipanah, 19 $\square$ Tashayoee, 2005).

The question that when a pipe needs to be renovated is always a key issue for decision makers of the urban water systems. For optimal operation of water distribution networks, several methodologies can be found in the literature. Some of them use conceptual models which just prioritize the time for rehabilitation or replacement based on the break records (Shamir and Howard, 1979; Andreou et al., 1987; Andres, 1993; Skipworth et al., 2000; Tabesh and Karimi, 2006). In these models the hydraulic performance of the system is not considered as a decision parameter and priority of pipes which need replacement is not also determined. On the other hand, in some models, the available budget and hydraulic situation of the system were incorporated (Anderson et al., 1997; Hadzilacos et al., 2000; Madiec et al., 1996; Engelhardt et al., 2000). Crisis models are a group of prioritized models in which renovation program is determined based on the risk of pipe breaks and the critical effects of these accidents on the network (Deb et al., 1998). Most of the available documents are related to application of optimization procedures to identify the optimum time of rehabilitation or replacement considering hydraulic or budget constraints (Lei and Saegrov, 1998; Kleiner et al., 2001; Dandy and Engelhardt, 2006; Berardi et al., 2007; Soltani, 2009). Some models use mechanical and hydraulic reliability or water quality as the replacement criteria. In these models, hydraulic simulation of the system is required (Engelhardt et al., 2000). Environmental assessment and GIS-based models are used to evaluate the impact or performance of different phenomena on the surrounding environment (Abbaspour and Soltaninejad, 2004; Abbaspour et al., 2005; Salman Mahini and Gholamalifard, 2006; Zerrouqi et al., 2008). Recently, some geographic information system (GIS)-based models have been introduced for simulation and management of water systems (Schlüter and Rüger; 2007; Vairavamoorthy, 2007). There are also a few models which determine the renovation time using hydraulic and/or GIS software. Kleiner et al. (2001) determined appropriate time for pipe replacement using a mathematical analysis in which EPANET software (Rossman, 2000) was used for hydraulic simulation. According to the number of bursts occurred in the system, Poulton and Conroy (2001) used GIS to evaluate the replacement program. Alzamora et al. (2001) used a combined GIS and hydraulic model to manage the water system. Tabesh et al. (2004, 2009) and Burrows et al. (2001) presented a methodology to calculate the network leakage using a linked GIS and EPANET model. It can be seen that each of the previous researches has considered the problem from one point of view and does not consider a multi criteria procedure for this purpose.

This study aims to present a comprehensive methodology for network renovation and pipe replacement schemes. At first, an integrated GIS and hydraulic model is produced to be able to mix spatial data with hydraulic and quality parameters of the network. A methodology is then presented which consists of different criteria such as break rates, potential leakage of the pipes, performance indicators based on pressure, velocity and residual chlorine values and reliability indices, to be used by decision makers in a pipe rehabilitation and replacement program. The model is applied on data sets gathered from Chaloos city (North of Iran) during non revenue water (NRW) studies at 1999 (Abran, 2000). It is observed that application of this GIS-based tool leads to better understanding of the problems of water networks and improves the process of decisionmaking.

\section{MATERIALS AND METHODS}

\section{GIS model}

At the beginning, the network map is digitized by the AutoCAD software and topology is built by Arc Info. Using the Arc View software, the GIS ready map is linked with the attribute data.

\section{Hydraulic model}

Since evaluation of up-to-date hydraulic parameters and their effects on the other indices are very important to achieve a realistic decision regarding the rehabilitation program, a hydraulic simulation model is required. In this research, the EPANET software (Rossman, 2000) is employed because of its availability, popularity and capability to be linked with GIS models. As an advantage, the EPANET software is able to simulate both hydraulic and quality of the system.

\section{Integrating hydraulic and GIS models}

At this stage both EPANET and Arc View software are linked. Transition software of Make (2001) was considered to link the GIS and hydraulic analyzer. Also a subroutine by the Avenue language was written to link the quality analyzer of the EPANET to the Arc View. 


\section{Decision criteria}

Several indices may be considered by the decision makers to determine the most vulnerable pipes for rehabilitation or replacement. In this study, the following criteria are applied which can be evaluated by the produced integrated model and represent the map of the candidate pipes to be rehabilitated or replaced.

\section{Burst analysis}

Bursts and accidents records are the most important parameters which currently are used by the network managers to identify the candidate pipes for rehabilitation and replacement. However, instead of a simple index of number of bursts in some parts of a network, two types of linear and non-linear regression are considered for break rates to show the priority of renovation scheme. For linear regression the following equation is used:

$$
\hat{y}=\beta_{0}+\beta_{1} x
$$

where,

$$
\begin{array}{lrr}
\beta_{0}=\bar{y}-\beta_{1} \bar{x} \quad \text { and } & \beta_{1}=\frac{S X Y}{S X X} . \\
S X Y=\sum x_{i} y_{i}-n(\bar{x} \bar{y}) & , & S X X=\sum x_{i}^{2}-n(\bar{x})^{2},
\end{array}
$$

$\bar{y}=\frac{\sum y_{i}}{n}, \bar{x}=\frac{\sum x_{i}}{n}, x_{i}$ and $y_{i}$ are observed values

of $X$ and $Y$ for $i=1,2, \ldots, n$, respectively. $n$ is the number of samples.

Using $\mathrm{F}$ evaluation (Eq. 2) based on the variance table, the regression patterns are compared and their appropriateness for linear regression is determined.

$F=\frac{M S}{M S E}=\frac{M S / 1}{S S E /(n-2)}$

where, $M S=\frac{(S X Y)^{2}}{S X X} \quad, \quad S S E=S Y Y-\frac{(S X Y)^{2}}{S X X}$ and $S Y Y=\sum y_{i}^{2}-n(\bar{y})^{2}$.

To evaluate the validation of regression types, the correlation coefficient is calculated as follows:

$$
r_{x y}=\frac{S X Y}{\sqrt{(S X X)(S Y Y)}}
$$

Non linear regression is determined as:

$\hat{y}=c d^{x}$

where, $c=10^{\beta_{0}}$ and $d=10^{\beta_{1}}$.

Mechanical reliability and pipe availability

Reliability is another criterion to evaluate the pipe and network situation. Mechanical reliability is the probability that any component continues its duty without any failure in time $[0, t]$. In repairable components, availability is preferred to reliability (Mays, 1989):

$$
a_{l}=\frac{M T B F}{M T B F+M T T R}
$$

where, $a_{l}$ is the availability of pipe $l$. MTBF and MTTR are the mean time between failure and mean time to repair.

Several formulas have been expressed for availability based on pipe diameter and length (Tabesh, 1998). The proposed model in this study is able to calculate pipe availability using different parameters, as shown in Eq. 6 (Fujiwara and Tung, 1991):

$a_{l}=\frac{\alpha_{l}}{\alpha_{l}+\beta_{l}}$

where, $\alpha_{l}$ is the number of repairs per day. $\beta_{l}=l_{l} \mu_{l}$

where, $l_{l}$ is the pipe length and $\mu_{l}$ is the pipe break rate per km (unit length of pipe) per year. All the required data to calculate pipes break rate and availability are obtained by GIS from bursts and repairs records in the study area.

\section{Leakage evaluation}

Although the real leakage points are identified through an expensive leak detection program, but using the combined hydraulic and GIS models the potential pipes and nodes for leakage can be determined. Leakage may be calculated by the following equation (Germanopoulos, 1985):

$\operatorname{Leak}_{i j}=C . L_{i j}\left(P_{i j}^{a v}\right)^{1.18}$

where, Leak $k_{i j}$ is pipe leakage discharge. C is a coefficient related to the network characteristics. $L_{i j}$ and $P_{i j}^{a v}$ are pipe length and the average pressure in pipe $i j$, respectively. 
Pressure values are calculated by the hydraulic model and are calibrated using the measured values stored as the attribute data in the GIS model. At the next stage, based on the minimum night flow (MNF) method, the leakage rate at MNF time (Leak ${ }_{\mathrm{MNF}}$ ) is calculated by deducting the legitimate night consumptions from the MNF. Then the time-based leakage values (Leak) are obtained (Lambert, 1997),

$$
\text { Leak }_{t}=\text { Leak }_{M N F} \times\left(A Z P_{t} / A Z N P_{M N F}\right)^{N}
$$

where, $\mathrm{AZP}_{\mathrm{t}}$ and $\mathrm{AZNP}_{\mathrm{MNF}}$ are the average zone pressure values at times $t$ and MNF, respectively. The daily leakage rate is obtained by summation of the (Leak) values through $24 \mathrm{~h}$. $\mathrm{N}$ is determined from the burst records based on the fixed and variable area discharge method (FAVAD) (Lambert, 1997).

Pipe lengths can be obtained through GIS attribute data. The $\mathrm{C}$ value is determined from MNF measurement records and finalized through a calibration procedure. Eq. 9 is applied for the first estimation of coefficient C (Tabesh et al., 2009).

$$
C=\frac{\text { Leak }_{M N F}}{\sum_{i=1}^{N J}\left(\sum_{j=1}^{N P} \frac{L_{i j}}{2} \times P_{i}^{N}\right)}
$$

Where NJ is the number of nodes and NP is the number of pipes connected to node $\mathrm{i}$. $\mathrm{P}_{\mathrm{i}}$ is the pressure in node i.

For leakage calculation necessary modifications are made in the EPANET software based on the proposed methodology (Eqs. 8 and 9 and MNF method). It should be mentioned that the EPANET software is just able to simulate leakage by ordinary orifice equation $\left(\mathrm{Q}=\mathrm{KP}^{0.5}\right)$, however, it suffers from lack of strong theoretical background to determine coefficient of $\mathrm{K}$ and pressure power of N. Finally, the resulting $\mathrm{C}$ value is stored in the GIS and the potential leakage value for each pipe is calculated inside the GIS using Eq. 7.

\section{Hydraulic and quality performance indicators}

Hydraulic performance indicators are appropriate indices to decide about any rehabilitation activities and improving the network performance (Alegre et al., 2006). Performance of each element such as node or pipe is evaluated using some penalty curves for hydraulic parameters of nodal pressure and pipe velocity. In this research, a penalty curve for pressure (Fig. 1) based on pressure dependent analysis has been produced. In Fig. $1\left(\mathrm{H}^{\mathrm{min}}\right)$ is the absolute minimum pressure head below which no flow can be discharged

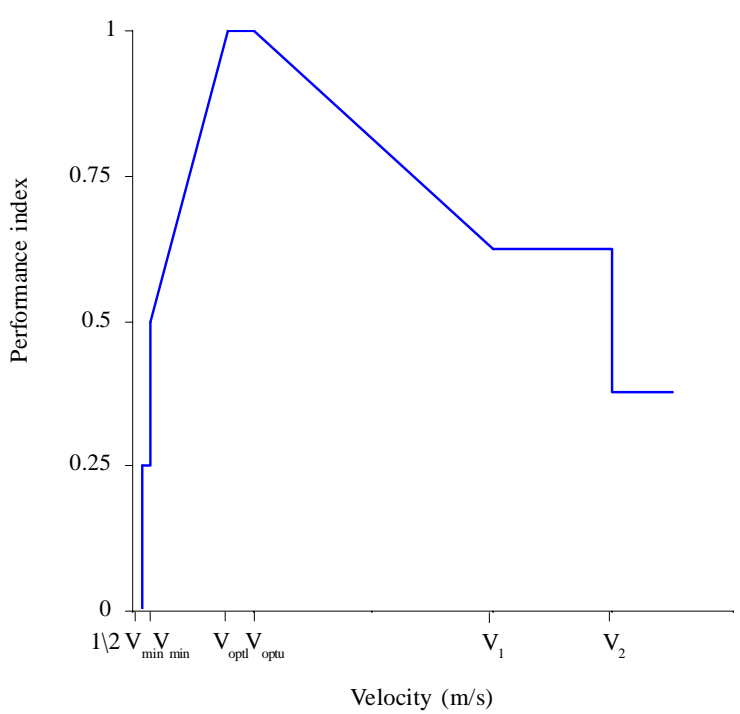

Fig. 2: Velocity penalty curve

Fig. 1: Penalty curve for nodal pressure 
and may be taken as the minimum outlet level in the locality served by the node. In the absence of field data it may be set equal to ground elevation. $\left(\mathrm{H}^{\mathrm{des}}\right)$ is the desired standard pressure head below which the nodal demand cannot be totally satisfied. Finally $\left(\mathrm{H}^{\max }\right)$ is the maximum acceptable pressure value extracted from the standard codes (IMPO, 1992).

The following values are considered for those parameters in this research: $H^{\min }=0, \mathrm{H}_{1}=\frac{1}{16} H^{\text {des }}$, $\mathrm{H}_{2}=\frac{1}{4} \mathrm{H}^{\mathrm{des}}, \mathrm{H}_{3}=\frac{9}{16} \mathrm{H}^{\mathrm{des}}, \mathrm{H}^{\mathrm{des}}=15-30 \mathrm{~m}$ and $\mathrm{H}^{\max }=50-70 \mathrm{~m}$.

Performance indices of $1,0.75,0.5,0.25$ and 0 are indicators of excellent, good, acceptable, unacceptable and no service situations. Also, performance of pipe velocity is evaluated by penalty curve of Fig. 2. Velocity values are obtained from standard codes (IMPO, 1992). The following values are considered in this paper: $\mathrm{V}$ $=0.3(\mathrm{~m} / \mathrm{s}), \mathrm{V}_{\text {optl }}=0.8(\mathrm{~m} / \mathrm{s}), \mathrm{V}_{\text {optu }}=1-1.2(\mathrm{~m} / \mathrm{s}), \mathrm{V}_{1}=2-2.5$ $(\mathrm{m} / \mathrm{s}), \mathrm{V}_{2}=4-5(\mathrm{~m} / \mathrm{s})$.

Besides the hydraulic parameters, the quality performance of WDS may be evaluated to identify the required improvements of the system. There are several quality parameters such as residual chlorine, water age and fluoride which can represent the water distribution system (WDS) quality situation. Residual chlorine is one of the most common parameters measured and evaluated in pipe networks all over the world. Fig. 3

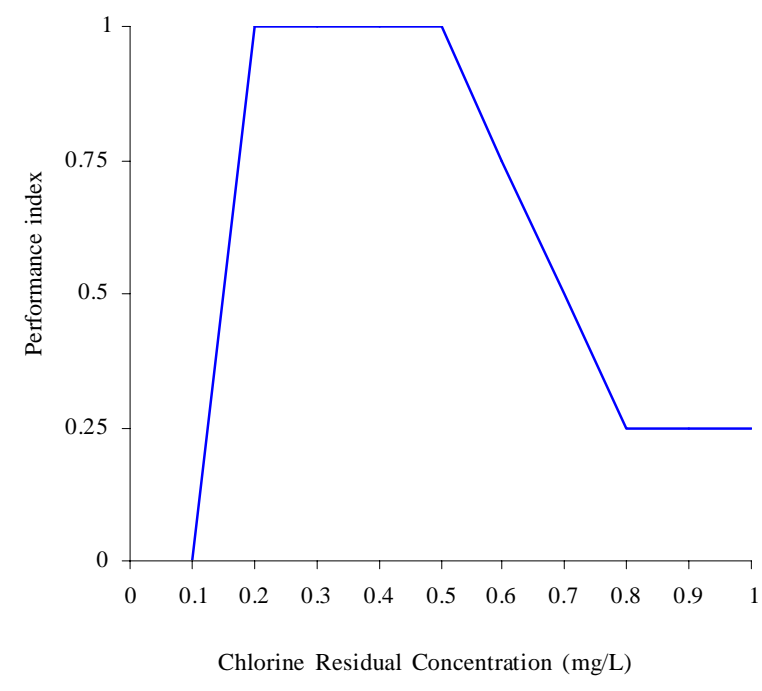

Fig. 3: Penalty curve for nodal residual chlorine shows a penalty curve to indicate the performance of the system based on residual chlorine at each node (Coelho, 1996).

Values of nodal pressure, residual chlorine and pipe velocity are determined by the hydraulic simulator and transferred to the GIS database. To generalize the element performance to the entire network the following functions are applied. in which $\mathrm{D}_{\mathrm{ij}}$ and $\mathrm{L}_{\mathrm{ij}}$ are diameter and length of pipe ij, respectively.

$P I_{N}=\frac{\sum_{j \in N J} Q_{j}^{r e q} \cdot\left(P I E_{j}\right)}{\sum_{j \in N J} Q_{j}^{r e q}} \quad$ or $\quad P I_{N}=\frac{\sum_{i j \in N P} \bar{V}_{i j} \cdot P I E_{i j}}{\sum_{i j \in N P} \bar{V}_{i j}}$

where, $P I_{N}, P I E_{j}$ and $P I E_{i j}$ are network and element (node or pipe) performance indices, respectively.

$Q_{j}^{r e q}$ is the nodal demand and the pipe volume is $\bar{V}_{i j}=\frac{\pi D_{i j}^{2} L_{i j}}{4}$.

To calculate the performance indicators a program has been written in Avenue language to perform all the calculations in the GIS model directly (Delkhah, 2003). Besides, the model is able to determine all the costs for field activities such as required repair, pipe rehabilitation or replacement for different pipe sizes and types.

The procedure of the integrated model which is used for management and modeling of the WDS is as follows: The spatial and attribute data extracted from the field

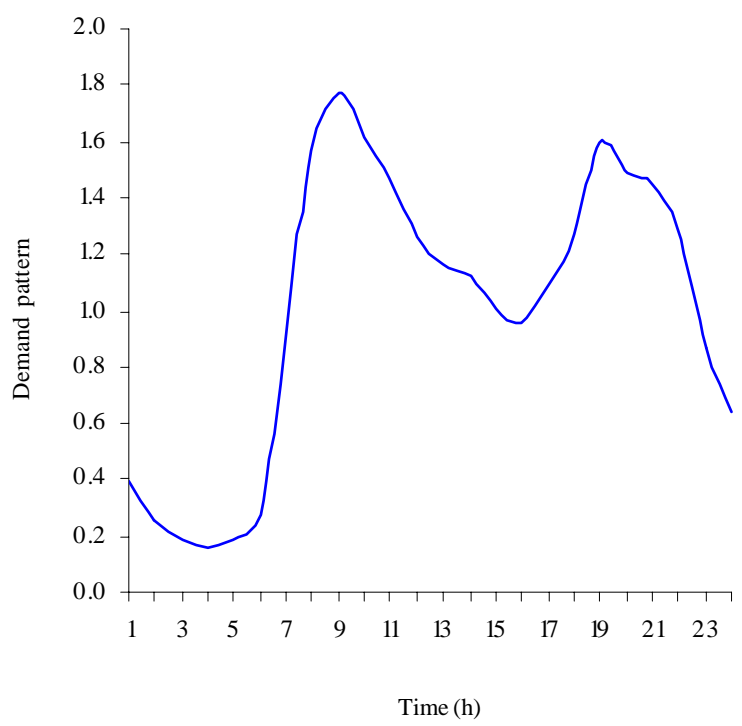

Fig. 4: The network demand pattern 
are entered into the integrated model. Then interface tables and topology are built by GIS. After the system analyses and required queries based on the proposed criteria by the integrated model, the results are assessed. If hydraulic or quality parameters need to be updated, new attribute data are produced by re-running the hydraulic model. Otherwise, the results can be used by decision makers for optimum planning and management of the system.

\section{RESULTS AND DISCUSSION}

To evaluate the advantage of the integrated model and the proposed methodology a pipe network in Chaloos is selected and a comprehensive study has been carried out. This complex network is placed in a 76.5 (ha) area, including 1533 connections with average demand of 28.8 ( $\mathrm{m}^{3} /$ month/connections), 438 pipes, 364 nodes, 1 reservoir and 91 valves. The pipe data is shown in Table 1.

All the required data from the network such as length, diameter, type, depth, resistance coefficient, year of laying, bursts of pipes, pressure, consumption and elevation of nodes, together with valves, pumps and reservoir information were gathered and stored in the database. Using the digitized map of the network and the above-mentioned database, AutoCAD, Arc Info and Arc View software, the GIS model was built.

To simulate hydraulics of the system, the modified EPANET simulator of the integrated software generates all the hydraulic and quality parameters such as nodal pressures and residual chlorine, pipes velocity and head loss at each hour using the demand pattern presented in Fig. 4.

\section{Burst analysis}

To determine the renewal program all the burst records were gathered and investigated. Using the GIS model all the pipes with burst records can be easily identified, marked and highlighted on the map. This map is a key tool to identify the potential area with highest burst records for replacement program. The model is also able to identify position of the valves required to be isolated for burst repair.

On the other hand, Table 2 shows pipe burst records and pipe break rates for a period of one year. It can be seen that GA pipes with 60 and $40 \mathrm{~mm}$ diameters have the highest break rate and are the first candidate to be replaced. The results indicate that use of number of burst to decide about the replacement scenario misleads the decision makers, because it introduces replacement of AC pipes with $100 \mathrm{~mm}$ diameter. However, because of longer length of AC $100 \mathrm{~mm}$ pipe it has lower priority.

Two types of linear and nonlinear statistical analyses are carried out on the pipe burst records. All the regression parameters for both types of analyses are calculated by the model and are represented in Table 3. For example the relationships of N.B. $=68.1667-0.35 \mathrm{D}$ and N.B. $=668.1(0.971)^{\mathrm{D}}$ with high correlation values are obtained by linear and non linear regression methods, respectively for AC pipes (N.B. is number of bursts). Negative sign of the correlation values indicates that number of bursts is decreasing when pipe diameter is increased. To validate the results, the F test is used by the model. In this analysis using table of variance, a value for $\mathrm{F}$ is obtained and compared with the value of $\mathrm{F}$ distribution with degree of freedom $(1, n-2)$ for the error of $p$. If $F$ is greater than $F$ distribution value, then regression with error level of $\mathrm{p}$ is valid. Cells include no value indicate unacceptable results of regression method for special pipe type and diameter.

\section{Availability index}

Applying the suggested method for pipe availability and results of pipe bursts and break rates from the previous section, the GIS model calculates the availability values for each pipe. Results show that for each pipe type, availability is increased when pipe length is increased and/or pipe diameter is decreased. It can be seen that for lower pipe lengths, availability is higher and also for higher diameters availability is increased.

Furthermore, the model can produce the appropriate formulation for pipe availability. Based on the available information in the model, values of availability are calculated for each pipe. Therefore, considering any critical threshold values for the availability, pipes with lower availability values can be candidated for rehabilitation and replacement. For instance, the following relationship is obtained for GA pipes:

$$
a_{l}=\frac{0.106}{0.106+L_{l} \mu_{l}}=\frac{0.106}{0.106+L_{l}\left(6.91885+0.0579 D_{l}\right)}
$$

where, $\alpha_{l}=\frac{39}{365}=0.106$ (number of repairs per day) and $\mu_{l}=6.91885-\left(0.0579 D_{l}\right)$ (break rates). $D_{l}$ and $L_{l}$ are pipe diameter $(\mathrm{mm})$ and length $(\mathrm{km})$, respectively. 


\section{Leakage analysis}

Applying the proposed methodology, the model calculates and distributes the expected leakage values among the pipes and nodes. At first a value is assumed for $\mathrm{C}$ based on Eq. 9. Then leakage of each pipe and entire network is calculated and compared with the measured value based on a minimum night flow analysis. Finally, based on the Eq. 9, the $\mathrm{C}$ factor is evaluated as $25 \times 10^{-5}$ for this network. The calculated leakage values are added to the model database. Then the leakage profile through $24 \mathrm{~h}$ and the leakage map which illustrates high risk points are drawn (Figs. 5 and 6). The leakage map is a good tool to decide about the pipes which should be replaced. According to the model outputs, there is one GA pipe (L1138) with 40 mm diameter, high leakage and more than 21 years age which need to replacement. This scenario requires 105 $\mathrm{m}^{2}$ removing of ground surface and excavation of 183 $\mathrm{m}^{3}$ that costs about 19,483,060 Rial (about 2,300 USD). All values are directly produced by the model.

Table 1: Pipe data

\begin{tabular}{|c|c|c|c|c|}
\hline Type & Diameter $(\mathrm{mm})$ & No. of Pipes & Length $(\mathrm{km})$ & Total Lengths (m) \\
\hline $\begin{array}{l}\text { Asbestos } \\
\text { Cement } \\
\text { (AC) }\end{array}$ & $\begin{array}{l}100 \\
150 \\
200\end{array}$ & $\begin{array}{r}159 \\
44 \\
22\end{array}$ & $\begin{array}{r}11314 \\
2232 \\
1721\end{array}$ & 15267 \\
\hline $\begin{array}{l}\text { Galvanized } \\
\text { (GA) }\end{array}$ & $\begin{array}{l}30 \\
40 \\
60 \\
80\end{array}$ & $\begin{array}{l}17 \\
69 \\
57 \\
11\end{array}$ & $\begin{array}{r}855 \\
4024 \\
3515 \\
527\end{array}$ & 8921 \\
\hline $\begin{array}{l}\text { Poly } \\
\text { Ethylene } \\
(\mathrm{PE})\end{array}$ & $\begin{array}{r}63 \\
110\end{array}$ & $\begin{array}{l}44 \\
15\end{array}$ & $\begin{array}{r}1916 \\
998\end{array}$ & 2914 \\
\hline Sum. & & 438 & & 27102 \\
\hline
\end{tabular}

Table 2: Pipe burst and breaks rates

\begin{tabular}{|c|c|c|c|c|c|}
\hline Pipe type & Diameter (mm) & Length (m) & No. of Bursts & \multicolumn{2}{|c|}{ Break Rate (break/km/year) } \\
\hline \multirow{3}{*}{ AC } & 100 & 11.31 & 37 & 3.270 & \multirow{3}{*}{3.078} \\
\hline & 150 & 2.23 & 8 & 3.585 & \\
\hline & 200 & 1.72 & 2 & 1.162 & \\
\hline \multirow{3}{*}{ GA } & 40 & 4.02 & 20 & 4.971 & \multirow{3}{*}{4.371} \\
\hline & 60 & 3.51 & 14 & 3.983 & \\
\hline & 80 & 0.52 & 1 & 1.896 & \\
\hline
\end{tabular}

Table 3: The results of regression analysis for break rate and number of bursts

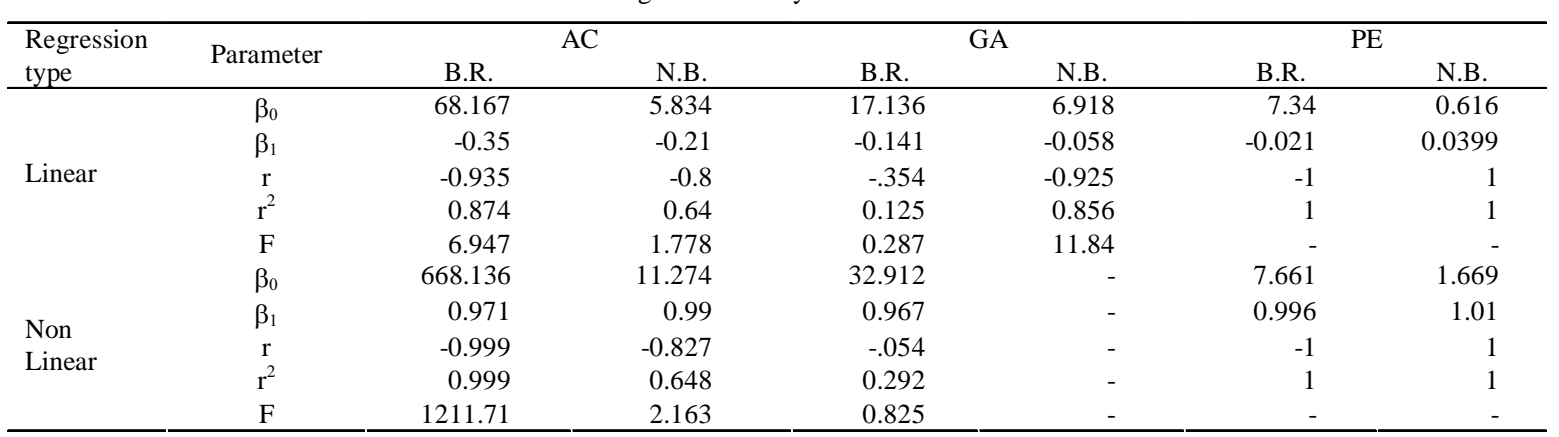




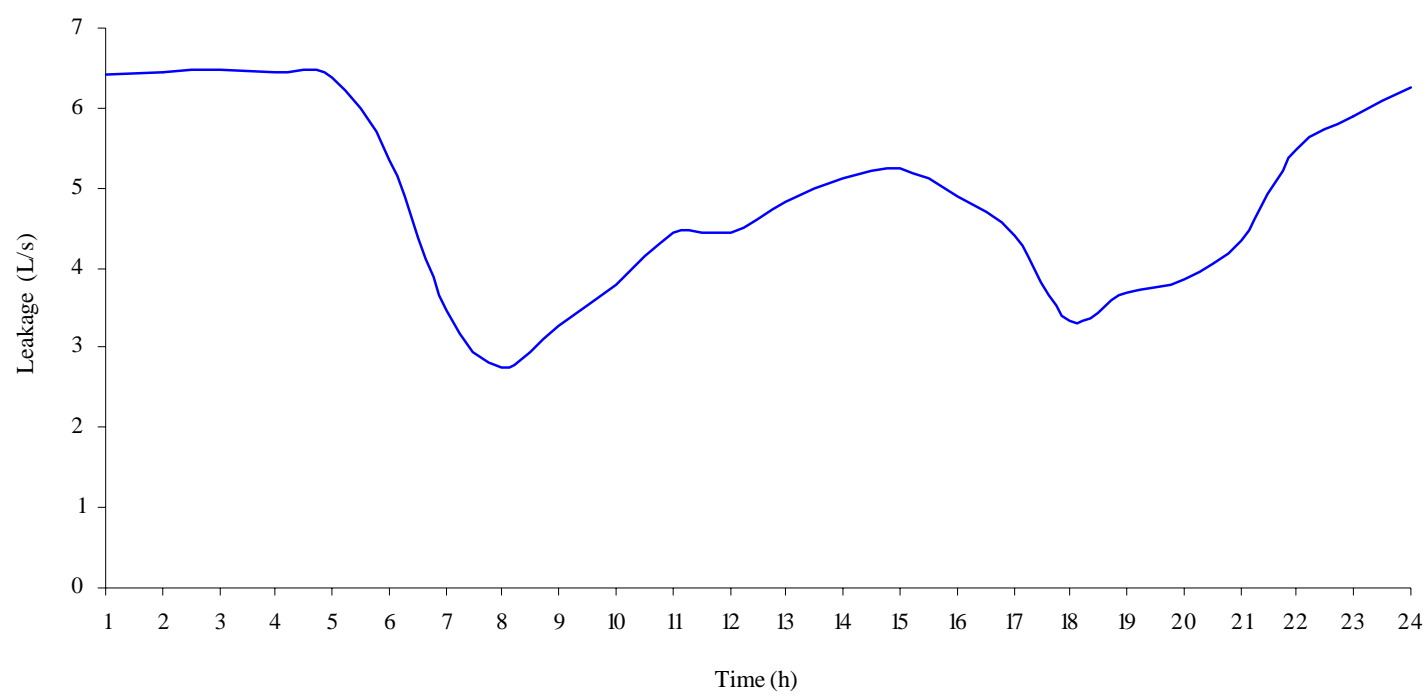

Fig. 5: The leakage profile for the network

\section{Performance indicators (PIs)}

Based on the results of network simulation for hydraulic and quality parameters and the proposed methodology for PIs, the performance indices for pressure, velocity and residual chlorine are calculated. Figs. 7 and 8 represent the pressure and velocity performance of the system. It can be seen in Fig. 7 that enough pressure exists in the network and network performance for pressure is good. However, some particular nodes such as J338 suffer from high pressure during night (Fig. 9). In contrast, performance indicator for velocity is not acceptable, especially at midnight that consumption is too low (Fig. 8). This situation is the result of poor design or weak operational management of the system during expansion scheme. Therefore, to improve the network performance some activities such as change of pipe diameter and discharge, or change in valve status or establishment of new valves may be considered by decision makers. The advantage of the proposed integrated model is that the suggested scenarios to improve the network or element performance can be evaluated and represented on the map and in the database, at first. Then the best one can be selected by the decision makers. Therefore, the limited available budget can be allocated to the best scenario which leads to the best performance. For instance, Fig. 10 illustrates the effects of changing diameter of pipe L1398 from 100 to $200 \mathrm{~mm}$ on the velocity performance. It can be seen that with replacing of a larger pipe size, the pipe performance is improved during the day, however, it leads to lower performance during the night because of the resulted very low velocity values.

Using the capabilities of the developed model, different representations regarding the nodes, pipes and network performance can be developed, for example for nodes with performance index less than acceptable level at the maximum and minimum consumption times, or points with pressure more than $50 \mathrm{~m}$ or less than $30 \mathrm{~m}$. Also when abnormal conditions are happened (e.g. pipe burst or accidents in the system), the model can evaluate the pressure performance of the network during repair time when the pipe is isolated from the network.

On the other hand, the network performance for nodal residual chlorine is calculated by the model. Maps can be provided to represent nodes with unacceptable performance indicator for residual chlorine which all of them are end nodes of different branches. It may be decided that to improve the residual chlorine performance, the time period, dosage or point of injection or any other decision which directly change the values of velocity to be varied. As mentioned earlier, when any decision is going to take place, the model is easily able to calculate all the rehabilitation costs to lead or assist the manager to the minimum cost action.

It should be mentioned that the conventional method which is currently used by water authorities to 
Int. J. Environ. Sci. Tech., 7 (1), 47-58, Winter 2010

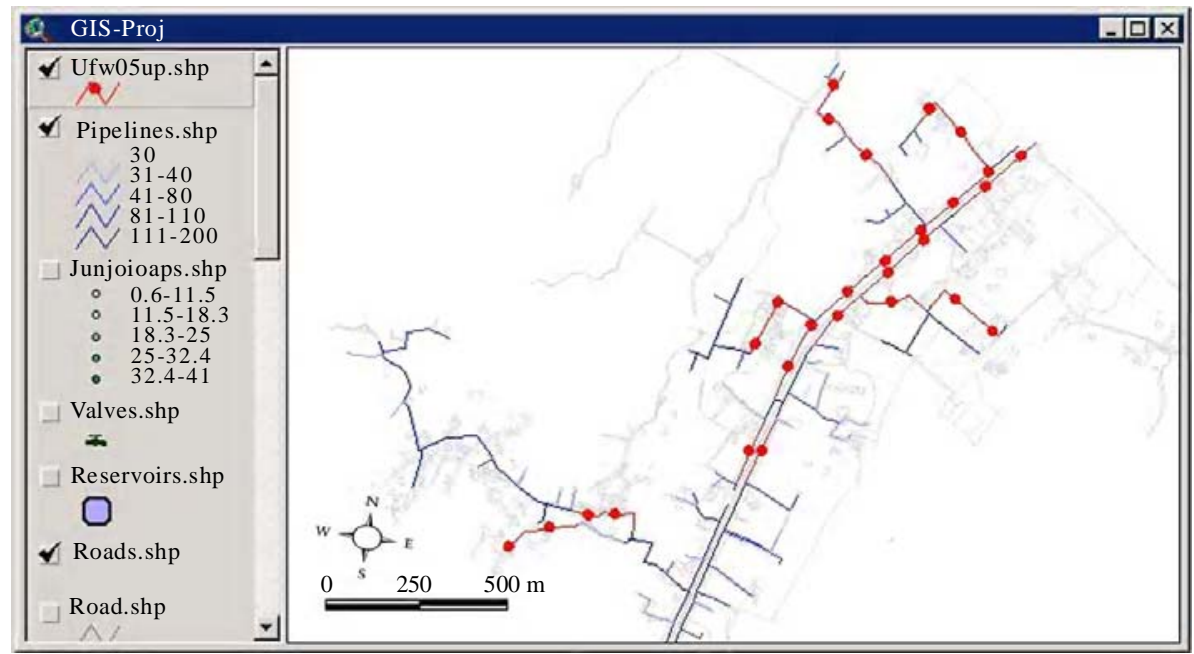

Fig. 6: Leakage map representing high risk points

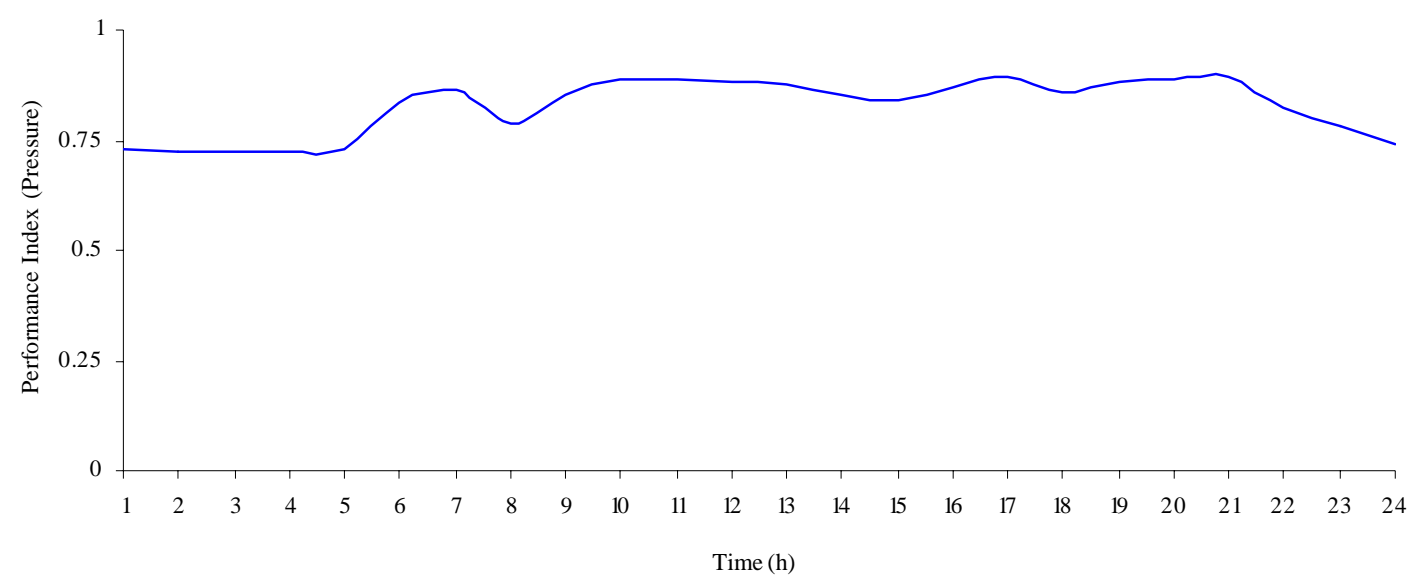

Fig. 7: Network performance for pressure

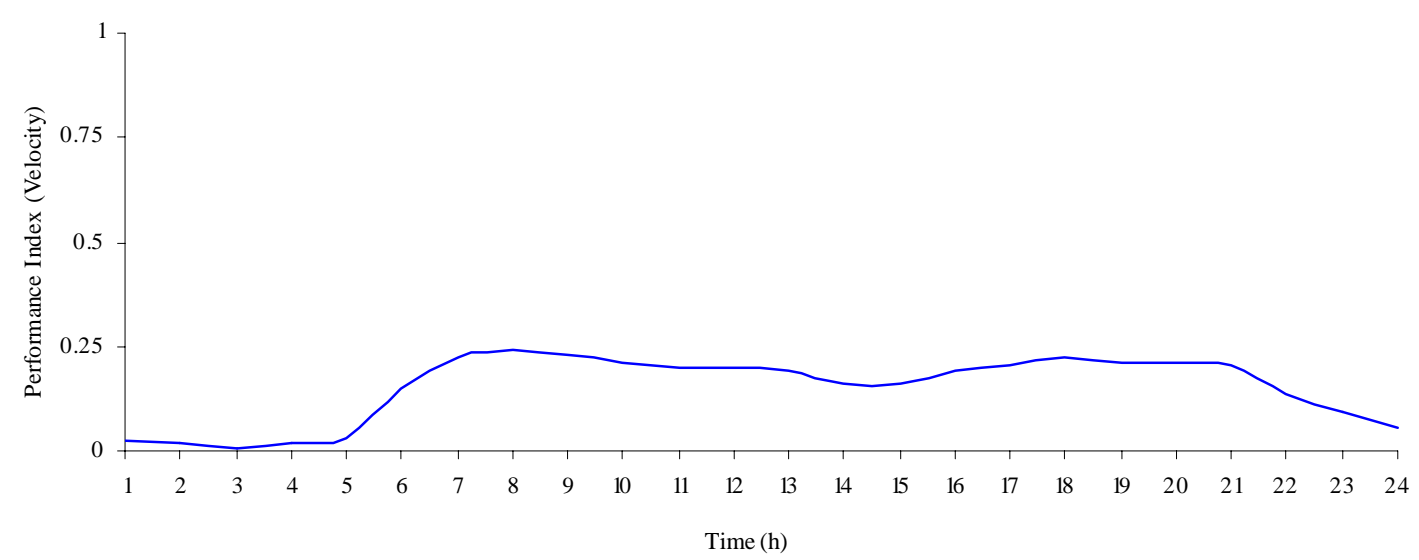

Fig. 8: Network performance indicator for velocity 
M. Tabesh et al.

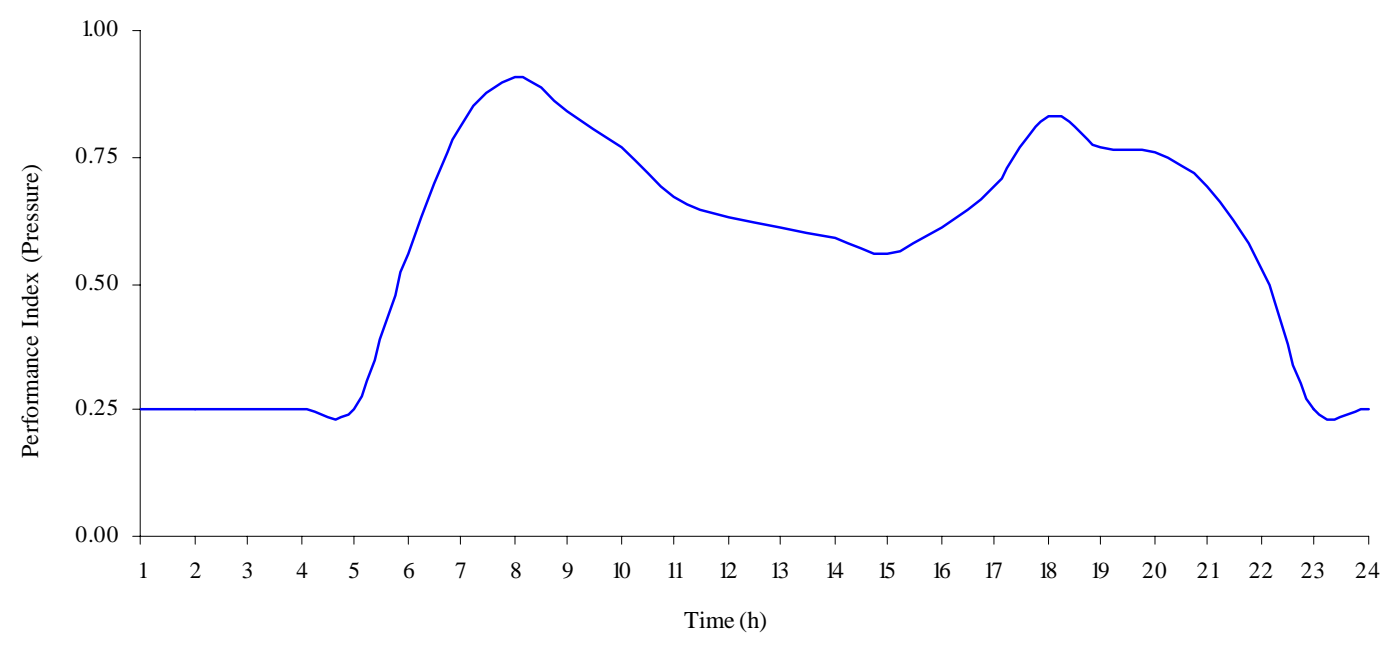

Fig. 9: Pressure performance of node J338

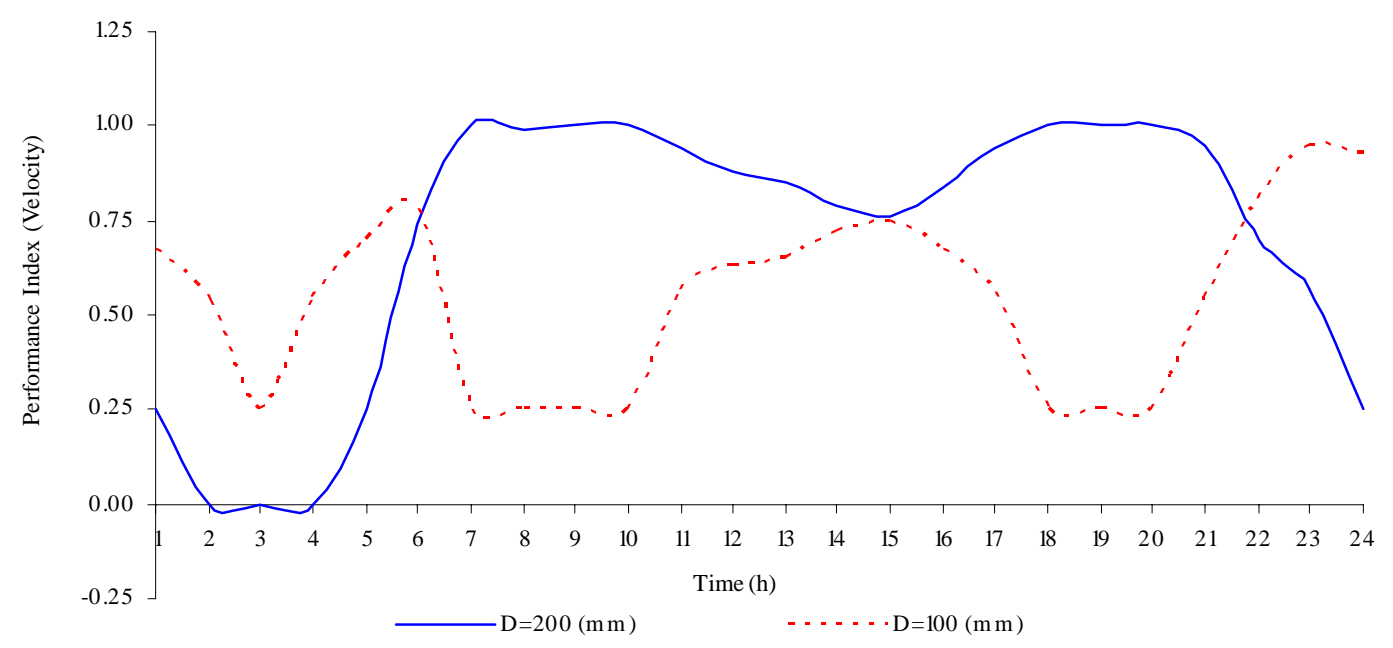

Fig. 10: The effects of changing diameter of pipe L1398 on the velocity performance

choose the renovation program is just based on measuring number of breaks. According to this method, AC pipes with $100 \mathrm{~mm}$ diameter and GA pipes with 40 and $60 \mathrm{~mm}$ diameters are the first options to be replaced. The proposed methodology produces different choices of decision-making based on different criteria which can be used separately or together based on the management targets. For instance, pipe break and leakage analyses and availability index are suggested for rehabilitation and replacement schemes.

Considering overlap bounds with high break rates, high leakage and low mechanical reliability produced by the GIS-based tool, the most vulnerable regions are introduced which include lower pipe diameters and longer lengths. On the other hand, performance indicators can be proposed for improving the hydraulic and quality situation of the system.

\section{CONCLUSION}

In this study, an integrated model was built which links the GIS and hydraulic simulation software. Then a robust and appropriate methodology for renovation and performance improvement of water distribution network was presented. This method consists of 
several parts such as calculating the number of breaks, break rates and burst analysis based on pipe diameter, length and leakage values. Using the performance indicators developed for hydraulic and quality parameters (pressure, velocity and residual chlorine), the performance of each node, pipe and entire network are evaluated and represented on the network map directly. Thus, the best scenario for rehabilitation and replacement of water network can be identified. Furthermore, the model calculates the cost of any operational decision. Results of the real case study showed that applying simple index of number of breaks is not a good criterion for pipe renovation scheme because the developed model introduced 4 $\mathrm{km} 40 \mathrm{~mm}$ GA pipes instead of $11 \mathrm{~km} 100 \mathrm{~mm}$ AC pipes from conventional method which leads to save huge amount of money. Furthermore, the model suggests the required pipes to be replaced to improve the hydraulic and quality performance of the network, because it is able to calculate and use the updated hydraulic and quality values from the simulation model.

\section{REFERENCES}

Abran Co., (2000). UFW studies in Chaloos water distribution network, Abran Consulting Engineers Co., Tehran, Iran.

Abbaspour, M.; Soltaninejad, A., (2004). Design of an environmental assessment model on the effect of vehicle emission in greater Tehran on air pollution with economic sensitivity. Int. J. Environ. Sci. Tech., 1 (1), 27-38 (12 pages).

Abbaspour, M.; Javid, A. H., Moghimi, P.; Kayhan, K., (2005). Modeling of thermal pollution in coastal area and its economical and environmental assessment. Int. J. Environ. Sci. Tech., 2 (1), 13-26 (14 pages).

Alegre, H.; Hirner, W.; Baptista, J. M.; Parena, R., (2006). Performance indicators for water supply services. IWA Publisher, 320.

Alzamora, F. M.; Ayala, H. J. B.; Roca, N. M., (2001). Connecting ArcView3.2 to EPANET2 - A full environment to manage water distribution systems using models. In Proceeding of the CCWI (2001): Water Software Systems: Theory and Applications, Ulanichi, B.; Coulbeck, B.; Rance, J. (Eds.), 2, 355-368.

Anderson, M. J.; Scott, R.; McManamon, P., (1997). Applying condition and criticality to develop efficient inspection, maintenance and renewal programs. In: Proceeding of the $17^{\text {th. }}$ AWWA Federal Convention, Melbourne, Australia, 674679 (6 pages).

Andreou, S.; Marks, D.; Clark, R., (1987). A new methodology for modelling break failure patterns in deteriorating water distribution systems: Theory. J. Adv. Water Resour., 10 (1) 2-10 (9 pages).

Andres, M., (1993). Water losses versus optimal life of a water distribution system's network. In: Water supply systems: State of art and future trends, 381-410 (30 pages).
Baygi, F., (1999). Vulnerability of water distribution networks. J. Water Environ., 37 (4) , 17-25 (9 pages).

Berardi, L.; Giustolisi, O.; Primativo, F., (2007). Exploiting multi-objective strategies for optimal rehabilitation planning”, Proceedings of Computer and Control in Water Industry (CCWI), Water Management Challenges in Global Changes, Ulanicki (Eds.), Taylor and Francis Group, 23-30.

Burrows, R.; Crowder, G. S.; Zhang, J., (2001). Application modeling for operational management of water distribution systems. In: Proc. of Water Industry Systems: Modeling and Optimization Applications, D. Savic (Ed.), 229-241.

Coelho, S. T., (1996). Performance assessment in water supply and distribution., Ph.D. Thesis, Department of Civil Engineering, University of Heriotwatt, UK.

Dandy, G. C.; Engelhardt, M. O., (2006). Multi-objective tradeoffs between cost and reliability in the replacement of water mains., J. Water Res. PL-ASCE., 132 (2), 79-88 (6 pages).

Deb, A. K.; Hasit, Y. J.; Grablutz, F. M.; Herz, R. K., (1998). Quantifying future rehabilitation and replacement needs of water mains. AWWA Resear. Found., 156.

Delkhah, A., (2003). Management and modelling of water distribution networks rehabilitation using GIS., M.Sc. Thesis, Department of Survay and Geomatic Engineering, Faculty of Engineering, University of Tehran, Tehran, Iran.

Elahipanah, N. A., (1998). Perspective of water distribution networks of Iran by year 2025. J. Water Environ., 28 (4), 4-15 (12 pages).

Engelhardt, M. O.; Skipworth, P. J.; Savic, D. A.; Saul, A. J.; Walters, G. A., (2000). Rehabilitation strategies for water distribution networks: A literature review with a UK perspective. Urban Water, 2 (2), 153-170 (18 pages).

Fujiwara, O.; Tung, H., (1991). Reliability improvement for water distribution network through increasing pipe size. J. Water Resour. Res., 27 (7), 1395-1402 (8 pages).

Germanopoulos, G., (1985). A technical note on the inclusion of pressure dependent demand and leakage terms in water supply network models. Civil. Eng. Environ. Sys., 2 (3), 171-179 (9 pages).

Hadzilacos, T.; Kalles, D.; Preston, N.; Melbourne, P.; Camarinopoulos, L.; Eimermacher, M.; Kallidromitis, V.; Frondistou-Yannas, S.; Saegrov, S., (2000). Utilnets: A water main rehabilitation decision-support system. Comput. Environ Urban Sys., 24 (3), 1-18 (18 pages).

IMPO, (1992). Standard code for design of urban water supply projects. Iran Management and Planning Organization. Report 117-3, Tehran, Iran.

Kleiner, Y.; Adams, B. J.; Rogers, J. S., (2001). Water distribution network renewal planning. J. Computat. Civil. Eng., ASCE., 15 (1), 15-26 (11 pages).

Lambert, A., (1997). Pressure management/leakage relationships: Theory, concepts and practical applications. In proceeding of minimizing leakage in water supply/ distribution systems, IQPC Seminar, London.

Lei, J.; Saegrov, S., (1998). Statistical approach for describing failures and lifetime of water mains. Water Sci. Tech., 38 (6), 209-217 (9 pages).

Madiec, H.; Botzung, P.; Bremond, B.; Eisenbeis, P., (1996). Implementation of a probability model for renewal of drinking water networks. Water Supply, IWSA (Durban), 14 (3-4), 347-351 (5 pages).

Make, S., (2001). DC Water design extension. Dorsch Consult, http://dcwaterdesign.sourceforge.net 
Mays, L. W., (1989). Reliability analysis of water distribution systems. ASCE, New York, N.Y.

Poulton, M. D.; Conroy, P. J., (2001). GIS-based analysis for selecting water distribution mains for rehabilitation. In

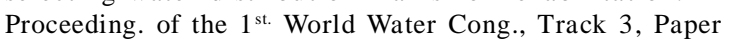
Eight, Berlin

Rossman, L. A., (2000). EPANET-2 user's manual. United States Envir. Prot. Agen.

Salman Mahini A.; Gholamalifard, M., (2006). Siting MSW landfills with a weighted linear combination methodology in a GIS environment. Int. J. Environ. Sci. Tech., 3 (4), 435-445 (10 pages).

Schlüter, M.; Rüger, N., (2007). Application of a GIS-based simulation tool to illustrate implications of uncertainties for water management in the Amudarya river delta. Environ. Model. Softw., 22 (2), 158-166 (9 pages).

Shamir, U.; Howard, C. D. D., (1979). An analytical approach to scheduling pipe replacement. J. Am. Water Works Assoc., 71 (5), 248-258 (11 pages).

Skipworth, P. J.; Saul, A. J.; Engelhardt, M. O., (2000). Distribution network behavior-extracting knowledge from data. In Proceeding of Int. Symp. on Water Network Model for Optimal Design and Management (CWS2000), University of Exeter, UK, 125-139.

Soltani, J., (2009). Optimal rehabilitation and replacement of water distribution networks using head driven simulation method and reliability constraint. Ph.D. Thesis, Faculty of Civil Engineering, University of Tehran, Tehran, Iran.

Tabesh, M., (1998). Implication of the pressure dependency of outflows on data management, mathematical modeling and reliability assessment of water distribution system. Ph.D. Thesis, Department of Civil Engineering University of Liverpool, UK.

Tabesh, M.; Bostanian, M. B.; Delavar, M. R., (2004). Application of integrated GIS and hydraulic models for unaccounted for water studies in water distribution systems. Int. J. Eng. Sci., 15 (2), 133-145 (13 pages).

Tabesh, M.; Karimi, K., (2006). Determination of leak detection and replacement time by analysis of pipes breaks records of water distribution networks. J. Faculty of Engineering University of Tehran, 40 (5), 597-610 (14 pages).

Tabesh, M.; Asadiyani Yekta A. H.; Burrows R., (2009). An integrated model to evaluate losses in water distribution networks. J. Water Resour. Manege., 23 (3), 477-492 (16 pages).

Tashayoee, H. R., (2005). Establishment of preventive and maintenance system for water distribution networks: disadvantages and outcomes., In Proceeding of the $3^{\text {rd. }}$ International Conference on Maintenance and Repair, Tehran, Iran.

Vairavamoorthy, K.; Yan, J.; Galgale, H. M.; Gorantiwar, S. D., (2007). IRA-WDS: A GIS-based risk analysis tool for water distribution systems. Environ. Model. Softw., 22 (7), 951965 (15 pages).

Zerrouqi, Z.; Sbaa, M.; Oujidi, M.; Elkharmouz, M.; Bengamra, S.; Zerrouqi, A., (2008). Assessment of cement's dust impact on the soil using principal component analysis and GIS. Int. J. Environ. Sci. Tech., 5 (1), 125-134 (10 pages).

\section{AUTHOR (S) BIOSKETCHES}

Tabesh, M., Ph.D., Associate Professor, Center of Excellence for Infrastructures Engineering and Management, School of Civil Engineering, College of Engineering, University of Tehran, Tehran, Iran. Email: mtabesh@ut.ac.ir

Delavar, M. R., Ph.D., Assistant Professor, Center of Excellence in Geomatics Engineering and Disaster Management, Department of Surveying and Geomatic Engineering, College of Engineering, University of Tehran, Tehran, Iran. Email: mdelavar@ut.ac.ir

Delkhah, A., M.Sc., Department of Surveying and Geomatic Engineering, College of Engineering, University of Tehran. Currently Kashan Water and Wastewater Company, Kashan, Iran. Email: alidelkhah@yahoo.com 